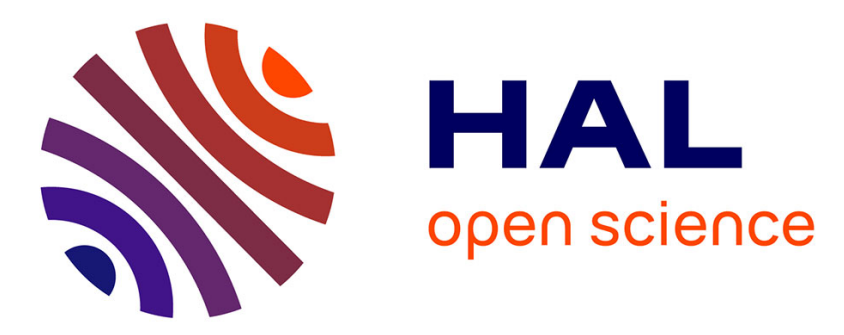

\title{
Treatment of drug-eluting stents in-stent restenosis with paclitaxel-coated balloon angioplasty: Insights from the French "real-world" prospective GARO Registry
}

V. Auffret, J. Berland, P. Barragan, M. Waliszewski, L. Bonello, N. Delarche, A. Furber, F. Albert, D. Carrié, H. Eltchaninoff, et al.

\section{To cite this version:}

V. Auffret, J. Berland, P. Barragan, M. Waliszewski, L. Bonello, et al.. Treatment of drug-eluting stents in-stent restenosis with paclitaxel-coated balloon angioplasty: Insights from the French "realworld" prospective GARO Registry. International Journal of Cardiology, 2016, 203, pp.690-696. 10.1016/j.ijcard.2015.11.031 . hal-01262682

\section{HAL Id: hal-01262682}

https://hal-univ-rennes1.archives-ouvertes.fr/hal-01262682

Submitted on 10 Mar 2016

HAL is a multi-disciplinary open access archive for the deposit and dissemination of scientific research documents, whether they are published or not. The documents may come from teaching and research institutions in France or abroad, or from public or private research centers.
L'archive ouverte pluridisciplinaire HAL, est destinée au dépôt et à la diffusion de documents scientifiques de niveau recherche, publiés ou non, émanant des établissements d'enseignement et de recherche français ou étrangers, des laboratoires publics ou privés. 


\section{Treatment of drug-eluting stents in-stent restenosis with paclitaxel-coated balloon angioplasty: insights from the French "real-world" prospective GARO Registry}

Authors: Auffret V, MD ${ }^{\mathrm{a}, \mathrm{b}, \mathrm{c}, 1}$, Berland J, MD, PhD ${ }^{\mathrm{d}, 1}$, Barragan P, MD, PhD ${ }^{\mathrm{e}, 1}$, Waliszewski M, MD ${ }^{\mathrm{f}, 1}$, Bonello L, MD, PhD ${ }^{\mathrm{g}, 1}$, Delarche N, MD ${ }^{\mathrm{h}, 1}$, Furber A, MD ${ }^{\mathrm{i}, 1}$, Albert F, $\mathrm{MD}^{\mathrm{j}, 1}$, Carrié D, MD, PhD ${ }^{\mathrm{k}, 1}$, Eltchaninoff $\mathrm{H}, \mathrm{MD}^{\mathrm{l}, 1}$, Pansieri $\mathrm{M}, \mathrm{MD}^{\mathrm{m}, 1}$, Schneeberger $\mathrm{M}, \mathbf{M D}^{\mathrm{n}, 1}$, Piot $\mathrm{C}, \mathrm{MD}, \mathrm{PhD}^{\mathbf{0 , 1}}$, Marcollet $\mathrm{P}, \mathbf{M D}^{\mathrm{p}, 1}$ and Bedossa $\mathrm{M}, \mathrm{MD}^{\mathrm{a}, \mathrm{b}, \mathrm{c}, *, 1}$

Authors' affiliations:

${ }^{\text {a }}$ CHU Rennes, Service de cardiologie et maladies vasculaires, Rennes, F-35000, France

${ }^{\mathrm{b}}$ INSERM, U1099, Rennes, F-35000, France

${ }^{\mathrm{c}}$ Université de Rennes 1, LTSI, Rennes, F-35000, France

${ }^{\mathrm{d}}$ Clinique Saint Hilaire Rouen, Service de cardiologie, F-76000, France

${ }^{\text {e }}$ Polyclinique Les Fleurs Ollioules, Service de cardiologie, F- 83190, France

${ }_{\mathrm{f}}^{\mathrm{f}}$ Medical Scientific Affairs, B.Braun Melsungen AG, Germany

${ }^{g}$ Département de Cardiologie Centre Hospitalo-Universitaire Nord, Marseille, F-13915, France.

${ }^{\text {h }}$ Centre Hospitalier de Pau, Service de cardiologie, F-64000, France

${ }^{i}$ Centre Hospitalier Universitaire Angers, Service de cardiologie, F-49100, France

${ }^{\mathrm{j}}$ Centre Hospitalier de Chartres, Service de cardiologie, F-28018, France

${ }^{\mathrm{k}} \mathrm{CHU}$ de Toulouse, Service de cardiologie, F-31059, France

${ }^{1}$ CHU de Rouen, Service de cardiologie, F-76000, France

${ }^{\mathrm{m}}$ Centre Hospitalier Avignon, Service de cardiologie, F-84000, France

${ }^{\text {n }}$ Hôpital Albert Schweitzer, Colmar, Service de cardiologie, F-68024, France

${ }^{\circ} \mathrm{CHU}$ de Montpellier, Service de cardiologie, F-34090, France

${ }^{\mathrm{p}}$ Centre Hospitalier de Bourges, Service de cardiologie, F-18000, France

${ }^{1}$ These authors take responsibility for all aspects of the reliability and freedom from bias of the data presented and their discussed interpretation.

* Corresponding author: Dr Marc Bedossa, Service de cardiologie et maladies vasculaires, CHU Pontchaillou, 2 rue Henri le Guilloux, Rennes, F-35000, France. Tel : +3329928 2505 ; Fax: +33299282503, marc.bedossa@chu-rennes.fr

Word count: 4497

Sources of Funding: This work received research funding from B.Braun Medical.

Number of tables: 6

Number of figures: 3 


\section{Abstract}

Background: Data about paclitaxel-eluting balloon (PCB) angioplasty to treat drug-eluting stents (DES) in-stent restenosis (ISR) were mainly collected in selected patient populations in the setting of randomized trials. The main goal of this prospective registry was to confirm the positive findings of these studies in an unselected population in clinical practice.

Methods: Consecutive patients with DES-ISR treated by PCB angioplasty were recruited in this prospective real-world registry. The primary endpoint was clinically driven target-lesion revascularization (TLR) at 9 months. Secondary endpoints included acute technical success, in-hospital outcomes, 9-month major adverse cardiac events (MACE) a composite of death, myocardial infarction (MI) and TLR and the occurrence of target vessel revascularization.

Results: A total of 206 patients $(67.7 \pm 10.2$ years, $80.6 \%$ male, $41.3 \%$ diabetics $)$ with 210 lesions were recruited. Unstable coronary artery disease was present in $55.3 \%$ of patients. The time from DES implantation to DES-ISR was 3.0 \pm 2.4 years. Quantitative analyses revealed that patterns of treated DES-ISR were focal in $55.7 \%$ and diffuse in $44.3 \%$. The reference diameter was $2.76 \pm 0.64 \mathrm{~mm}$. The 9-month follow-up rate was $90.8 \%$ (187/206). At 9 months, the TLR rate was $7.0 \%(13 / 187)$ whereas the rates for MACE, MI and cardiac death were $10.7 \%(20 / 187), 4.8 \%(9 / 187)$ and $2.1 \%$ (4/187) respectively. Results were consistent in patients with paclitaxel and non-paclitaxel-eluting stents (PES) ISR.

Conclusion: This large prospective registry demonstrated acceptable rates of TLR and MACE at 9 months after treatment of DES-ISR by PCB angioplasty. PCB angioplasty was equally effective in patients with PES-ISR and non PES-ISR.

Key words: drug-eluting stent in-stent restenosis, paclitaxel-coated balloon, target lesion revascularization 


\section{Introduction}

The introduction of drug-eluting stents (DES), through the dramatically decreased incidence of in-stent restenosis (ISR) it yielded, is considered a revolution in the field of percutaneous coronary intervention $(\mathrm{PCI})^{1}$. The further-improved safety profile of newgeneration DES led to their unrestricted use in increasingly complex patients and lesions ${ }^{2,3}$ so that latest European guidelines ${ }^{4}$ state that DES should be considered by default in all clinical conditions and lesion subsets. However, DES have not eliminated the ISR issue as a recent angiographic study shown that these new-generation devices are still plagued by a $12 \%$ rate of angiographic $\mathrm{ISR}^{5}$.

Paclitaxel-coated balloon (PCB) were initially studied in bare-metal stent (BMS) ISR against plain old balloon angioplasty $(\mathrm{POBA})^{6-9}$ or paclitaxel-eluting stent $(\mathrm{PES})^{10}$, since it appeared very attractive to locally deliver a drug without the introduction of additional stent layers. These studies showed an early and sustained benefit of PCB over POBA on angiographic and clinical outcomes whereas only a trend towards better clinical results was achieved against PES despite significantly improved angiographic findings with PCB. There are increasing data regarding treatment of DES-ISR by PCB angioplasty either compared to POBA $^{11,12}$, PES ${ }^{13}$ or both techniques ${ }^{14}$. These studies demonstrated that late lumen loss (LLL), diameter stenosis (\%) and major adverse cardiac events (MACE) were consistently and significantly lower in patients treated by $\mathrm{PCB}$ than in patients treated by POBA ${ }^{11,12}$. Moreover, PCB angioplasty matched the angiographic and clinical results of repeat stenting with $\mathrm{PES}^{13,14}$. These data recently led the European Society of Cardiology to give a class IA recommendation for the use of $\mathrm{PCB}$ in BMS and DES-ISR ${ }^{4}$. In this setting, the main goal of this observational study was to confirm these positive findings in an unselected French patient population under routine use. 


\section{Methods}

\section{Objectives}

The aim of the GARO (Groupe des Angioplasticiens de la Région Ouest) registry was to evaluate the safety and efficacy of PCB angioplasty to treat DES-ISR in native coronary arteries. This was a non-randomized, open-label, single arm, observational registry conducted in 13 French centers (see list in Appendix). The protocol was approved by the French national ethics committee as part of the parent 'All-Comers Registry' which also included other indications beside DES-ISR. All patients gave written informed consent. Data were captured using an established electronic case report form with built-in plausibility checks previously proved useful and efficient in related observational PCB studies ${ }^{15,16}$. The two coordinating investigators $(\mathrm{MB}, \mathrm{JB})$ were responsible to contact co-investigators whenever the e-CRF plausibility checks indicated discrepancies.

\section{Patients}

All consecutive patients $>18$ years old with DES-ISR, treated by PCB angioplasty were enrolled in this registry. All Mehran types of ISR $^{17}$ in native coronary arteries with reference vessel diameters between $\leq 2.5$ and $\leq 3.5 \mathrm{~mm}$ and $\leq 22 \mathrm{~mm}$ in length were eligible. ISR had to reduce the reference vessel diameter either by $\geq 70 \%$ or $\geq 50 \%$ with documented ischemia corresponding to the target lesion. Major exclusion criteria were: cardiogenic shock, Killip class III heart failure, pregnant/lactating women, severe valvular heart disease, patients with a life-expectancy $<5$ years and patients with contraindications to dual-antiplatelet therapy or known hypersensitivity to acetylsalicylic acid, clopidogrel, paclitaxel, or heparin. 


\section{Endpoints and definitions}

The primary endpoint was clinically driven target lesion revascularization at 9 months (TLR) as a composite of re-PCI and coronary artery bypass grafting (CABG). Secondary endpoints included the procedural success rate, definite acute/subacute vessel thrombosis rates as defined by the ARC criteria ${ }^{18}$. Moreover, major adverse cardiac events (MACE), defined as the composite of TLR, death of cardiac or unknown origin and myocardial infarction (MI), were also documented. Myocardial infarction was diagnosed with corresponding ECG changes and/or cardiac enzyme elevations according to each institution's routine diagnostic algorithms.

\section{Procedure}

Patients received $500 \mathrm{mg}$ of aspirin before the intervention or were receiving longterm treatment. A clopidogrel loading dose of 300-600 mg was administered. Heparin (50$100 \mathrm{UI} / \mathrm{kg})$ was administered upon insertion of the sheath. Intracoronary Nitrates $(0.2 \mathrm{mg})$ were administered 2 minutes before baseline and final reference angiography performed in two near-orthogonal views. The paclitaxel-coated $\left(3 \mu \mathrm{g} / \mathrm{mm}^{2}\right)$ PTCA catheter based on the Paccocath ${ }^{\circledR}$ Technology (SeQuent ${ }^{\circledR}$ Please, B.Braun Melsungen AG) was used accordingly to previously published guidelines ${ }^{19}$. Especially, special attention was given to proper predilation of the target lesion and PCB was not used unless residual diameter stenosis was $\leq$ $30 \%$ after balloon predilation. A $60 \mathrm{~s}$ PCB inflation at a minimum of 10 bar was recommended unless not tolerated by the patient (hypotension and/or severe ventricular arrhythmia due to ischemia). Additional stents were implanted in case of significant recoil, residual stenosis or dissections after PCB therapy. Lesion length and vessel reference diameter were assessed using online quantitative coronary angiography or visual estimation. Dual-antiplatelet therapy was recommended for at least 9 months after the procedure. 


\section{Quantitative Coronary Angiography}

Angiographic data were routinely collected pre- and post-procedure with the use of identical projections and analyses. Quantitative analysis of the coronary angiographic images was done by 2 independent operators in an independent angiographic core laboratory. A difference of $\pm 3 \%$ of the relative stenosis between the two operators was deemed acceptable. If the discrepancy exceeded this value, a third operator decided upon the result of the assessment. In case of insufficient quality of the angiogram, the patient was rejected. The CAAS II research system (Quantcor QCA, Pie Medical Imaging, Maastricht, The Netherlands) was used for automated contour detection and quantification.

\section{Statistical analysis}

Continuous variables are expressed as mean \pm SD. Normality was tested using Kolmogorov-Smirnov test. Continuous variables were compared using unpaired t-test or Mann-Whitney U-test as appropriate. Categorical variables are presented as counts and percentages and were compared with the use of Fisher's exact or $\chi^{2}$ test, as appropriate. Timeto-event data are shown as Kaplan-Meier curves and were compared using the log-rank test. Kaplan-Meier curves reports end-points that were censored at the time of first event or at 9 months, whichever occurred first. All reported p-value are 2-sided and a p-value $<0.05$ was considered significant. Analyses were done with SAS version 9.2 (SAS Institute Cary, NC USA) and SPSS version 20.0 (IBM, Munich, Germany). Subgroup analyses were planned for DES-ISR subgroups consisting of PES-ISR and non-PES-ISR due to potential differences in clinical outcomes. 


\section{Results}

Patients

From February 2011 to April 2013, a total of 206 consecutive patients (mean age: $67.7 \pm 10.2$ years; male sex: $80.6 \%$ ) were included in the present study. Diabetes mellitus was present in 85 patients (41.3\%), $143(69.4 \%)$ had hypertension, $156(75.7 \%)$ had hyperlipidemia and 97 (47.1\%) were current smokers. Thirty four patients (16.5\%) presented with MI and a total of 114 patients $(55.3 \%)$ had unstable coronary artery disease at presentation. The mean time from DES implantation to DES-ISR was 3.0 \pm 2.4 years. Table 1 summarizes baseline clinical characteristics of the study population and provides a comparison between patients with a PES-ISR $(n=42)$ and a non PES-ISR $(n=164)$. Both groups were comparable at the exception of a higher rate of unstable angina in the PES-ISR group $(43.3 \%$ vs. $21.4 \%, \mathrm{p}=0.009)$.

\section{Baseline angiographic characteristics (Table 2)}

The majority of patients had single-vessel disease $(56.8 \%)$ with a target lesion located in the left anterior descending artery in the left anterior descending coronary artery in $37.6 \%$, the left circumflex coronary artery in $27.6 \%$ and the right coronary artery in $29.0 \%$. The most represented target stent types were PES (21.2\%), sirolimus-eluting stent (SES, 38.4\%) and new-generation everolimus-eluting stent (EES, 29.1\%). Diffuse ISR pattern was present in $44.3 \%$ of patients.

Quantitative coronary angiographic analysis and procedural characteristics

The mean lesion length and reference vessel diameter were $12.59 \pm 8.87 \mathrm{~mm}$ and $2.77 \pm 0.78 \mathrm{~mm}$ respectively (Table 3 ). The mean residual stenosis diameter was $15.6 \pm 12.5 \%$ post-index procedure (Table 3). Diameter stenosis was smaller in the PES-ISR group 
(57.5 $\pm 17.2 \%$ vs. $67.2 \pm 16.4 \%, \mathrm{p}=0.002)$. However, this difference was not observed after the intervention $(14.6 \pm 11.1 \%$ vs. $15.9 \pm 12.8 \%, \mathrm{p}=0.575)$. There were also no post-procedural differences between groups in terms of reference vessel diameter $(p=0.446)$ and MLD $(\mathrm{p}=0.262)$.

The mean PCB length and diameter were $19.5 \pm 4.9 \mathrm{~mm}$ and $3.0 \pm 0.36 \mathrm{~mm}$ respectively. For treatment of 210 lesions, 227 PCB were used (1.07 PCB per lesion). The mean inflation pressure was $12.6 \pm 3.7$ bar. After PCB therapy, dissections were documented in 3 lesions $(1.4 \%)$ and 6 patients $(2.9 \%)$ necessitated additional stenting. Procedural characteristics are summarized in Table 4. Procedural success of the PCB interventions was reported for 207 lesions $(98.6 \%)$ with a borderline significant difference $(\mathrm{p}=0.046)$ between the PES-ISR and non-PES-ISR groups (Table 4).

\section{In-hospital and accumulated 9-months clinical events}

There were no differences between the PES-ISR and the non PES-ISR groups during hospitalization (Table 5). Overall there was only one cardiac death and one TLR up to the point of discharge. Complete follow-up (by telephone: $79.7 \%$ or by hospital visit: $20.3 \%$ ) was achieved in 187 patients $(90.8 \%)$ at a mean of $8.9 \pm 0.84$ months. The primary endpoint of TLR occurred in 13 patients (7.0\%) whereas $10.7 \%$ of patients suffered a MACE. 9-month rates of MI and cardiac death were $4.8 \%$ and $2.1 \%$ respectively (Figure 1, Table 5).

There was no difference between the PES-ISR and the non PES-ISR groups in the 9month rates of TLR $(3.6 \%$ vs. $7.0 \%, p=0.314)$, MACE $(7.2 \%$ vs. $9.2 \%, p=0.738)$, MI $(4.8 \%$ vs. $4.4 \%, \mathrm{p}=0.772)$, cardiac death $(4.8 \%$ vs. $1.4 \%, \mathrm{p}=0.791)$ as assessed by Kaplan-Meier method (Figure 2). Regarding TLR rates, these results were consistent across various subgroups. However, patients with a delay between DES implantation and DES-ISR $<12$ 
months presented a clear trend towards higher rate of MACE (Figure 3). Although, treatment of new-generation EES-ISR resulted in higher absolute 9-months rates of TLR $(9.7 \%$ vs. 4.7\%) and MACE (15.3\% vs. $6.8 \%)$, these differences did not reach statistical significance.

\section{Discussion}

The main finding of the present study is that PCB angioplasty to treat DES-ISR achieved acceptably low rates of TLR and MACE at 9 months in a French unselected patient population which is in agreement with previously conducted DES-ISR trials.

DES-ISR and BMS-ISR share some common mechanisms such as stent underexpansion, stent fracture, stent malapposition, and non-uniform strut distribution but DES-ISR also presents specific stimuli of neointimal thickening like localized hypersensitivity, non-uniform drug deposition, polymers and drug resistance ${ }^{20,21}$. This may explain why treatment of DES-ISR remains highly challenging. Indeed, a recent multicenter retrospective analysis of 392 patients with 481 DES-ISR lesions, which were treated with repeat DES stenting in $66 \%$ of cases, showed rates of recurrent restenosis ranging from 29.0 to $65.6 \%$ depending on the initial pattern of DES-ISR ${ }^{21}$. Some authors ${ }^{9,22}$ suggested that DESISR identifies a high-risk group of patients in which the best available antirestenotic therapy to date has failed and PCB angioplasty in this setting, like repeat DES stenting, has shown worse results than in the treatment of BMS-ISR ${ }^{9,12}$. The results of the present study showing higher absolute rates of TLR and MACE after treatment of new-generation EES-ISR support this idea of a very challenging group of patients exhibiting signs of resistance to our current "gold-standard".

Previous studies investigating the efficacy and safety of PCB angioplasty to treat DESISR reported rates of TLR ranging from $2.9 \%$ at 6 months $^{9}$ to $22.1 \%$ at 12 months ${ }^{14}$ and rates 
of MACE ranging from $6.6 \%{ }^{9}$ to $23.5 \%{ }^{14}$ at the same time points (Table 6). Thus, the clinical outcomes of the present study are in agreement with previously published trials ${ }^{9,11-14}$. Postprocedural diameter stenosis (Table 6) was $15.6 \pm 12.5 \%$ in our series which agrees well with the findings in the ISAR DESIRE $3^{14}(18.5 \pm 8.3 \%)$ and the PEPCAD DES ${ }^{12}(12.6 \% \pm 6.2 \%)$ trials. Even lower procedural diameter stenoses were reported by Xu et al. ${ }^{13}(10.5 \% \pm 7.2 \%)$ whereas Habara and coworkers documented the highest remaining degree of stenosis $(25.7 \% \pm 7.2 \%)$. These discrepancies seems attributable to lower post-procedural MLD in studies by Habara et al. ${ }^{9,11}$ which highlights the adamant importance of a proper pre-dilation of the lesion before using a PCB with regard to angiographic outcomes. These procedural results does not necessarily relate to clinical outcomes (Table 6) however they greatly influence the conclusion of studies using an angiographic measure at follow-up as their primary end-point. Intermodality studies comparing PCB angioplasty to repeat DES stenting might especially be prone to this bias as repeat stenting usually results in higher postprocedural $\mathrm{MLD}^{13,14,23}$. Moreover, the number of stent layers may introduce additional bias. Rittger et $\mathrm{al}^{12}$ reported that $53.6 \%$ of the ISR lesions treated in their patient population had at least 2 metal layers the latest being a DES which may explain the relatively high late lumen loss in the PCB and POBA groups $(0.43 \pm 0.61 \mathrm{~mm}$ vs. $1.03 \pm 0.77 \mathrm{~mm}, \mathrm{p}<0.001)$. Our belief is that a proper pre-dilation is of adamant importance in the setting of DES-ISR. Cutting and especially the more flexible and deliverable scoring balloons may be particularly attractive as they allow device anchoring in the lesion, deep incision of neointimal tissue and prevent "watermelon seeding" effect which might be responsible for edge dissection and unplanned stent implantation. Whether these devices provide better results in the treatment of DES-ISR is currently the subject of ongoing clinical trials (21).

Our finding that PCB angioplasty results in similar clinical outcomes after treatment of PES-ISR and non PES-ISR is in line with the conclusion of the ISAR-DESIRE 2 study $^{24}$. In 
this trial, 450 patients with 483 SES-ISR lesions were randomized to repeat DES stenting with either a SES or a PES. No differences were seen between the two strategies with regard to angiographic or clinical outcomes. On the contrary, the RIBS III (Restenosis Intra-Stent: Balloon Angioplasty Versus Drug-Eluting Stent) trial, a prospective multicenter registry including 363 patients with DES-ISR, demonstrated, after adjustment using propensity score analyses, a significant reduction of the composite of cardiac death, MI and TLR (hazard ratio: $0.56,95 \%$ CI: 0.33 to $0.96, p=0.038$ ) with the use of a switch strategy ${ }^{25}$. If overall data about the switch strategy remain inconclusive, an interesting point in the RIBS III trial is the suggestion of a superiority of second-generation DES over first-generation DES. Indeed, so far, studies and meta-analyses support non-inferiority of PCB angioplasty against firstgeneration $\mathrm{DES}^{10,13,14,26,27}$ but little is known about the comparative effectiveness of PCB and new-generation DES in DES-ISR. A recent study by Almalla et al. ${ }^{28}$ compared PCB angioplasty to EES implantation in an DES-ISR study population using a historic control arm and showed significantly lower TLR and MACE rates in the PCB group. Contrarily, in the setting of BMS-ISR, the RIBS V (Restenosis Intra-stent: Drug-eluting Balloon vs. Everolimus-eluting Stent) trial ${ }^{23}$, which recently provided the first randomized comparison of PCB angioplasty with second-generation EES in 189 patients, demonstrated improved angiographic results (LLL, diameter stenosis) after EES. However, binary restenosis rates were low and similar in both groups $(4.7 \%$ vs. $9.5 \%, \mathrm{p}=0.22)$ and these better angiographic results did not translate into improved clinical outcomes. Therefore, additional data are needed to define the respective roles of PCB angioplasty and EES implantation in the treatment of DES-ISR.

The time course between DES implantation and ISR seems to be an important factor to consider when addressing the issue of DES-ISR. We showed a higher rate of MACE in patients with a delay between DES implantation and DES-ISR $<12$ months. The shorter the 
time frame from DES implantation to DES-ISR is, the less likely ISR is to be caused by neointimal hyperplasia whereas mechanical factors probably play a crucial role. It has also been shown that early ISR presentation was correlated to diffuse ISR patterns which may explain the worse results we observed in the sub-group of patients with a short delay between DES implantation and ISR as the morphological pattern of DES-ISR is an important predictor of clinical outcomes, especially $\mathrm{TLR}^{20}$.

By definition a study limitation of all-comers registries is a less stringent control of data collection. Moreover, source data monitoring was only conducted whenever discrepancies were detected by the electronic data capture system. As a consequence, some under-reporting may have occurred in the present study. Owing to the evaluation of PCB angioplasty in routine clinical practice, we did not provide an angiographic follow-up and the database did not include information about intracoronary imaging techniques as their use to identify underlying mechanical factors was left to the discretion of the operator in this reallife setting. However, rates of $20 \%$ and even $42 \%$ of stent under-expansion were reported respectively in the setting of BMS-ISR (29) and DES-ISR (30). Thus, the crucial importance of identifying these mechanical issues cannot be enough emphasized to reach better results when dealing with DES-ISR.

\section{Conclusion}

PCB angioplasty to treat DES-ISR delivered an acceptably low 9-month TLR rate in a French unselected patient population which is in agreement with previously conducted DES-ISR trials. No difference was seen between PES-ISR and non-PES-ISR patients treated with PCBangioplasty. Cardiovascular and lesion related risk factors were not predictors of MACE. However, if DES-ISR occurred within 12 months the risk of MACE at 9 months was higher in these early DES-ISR patients after PCB angioplasty. 


\section{Acknowledgements}

The authors are indebted to all physicians who took part in the study. We also thank Denny Herberger (Medical Scientific Affairs, B.Braun Vascular Systems) and Dr. Ghislaine Martin (B.Braun Medical France) for their valuable logistic support. We are also very grateful to Yvon Berthelot and Norbert Persehaie for their continuous help for this study.

\section{Conflict of interest}

All participants received research funding from B.Braun for data acquisition and analysis purposes limited to this clinical assessment. Dr. M. Waliszewski is a full-time employee of B.Braun. 


\section{References}

1 Stefanini GG, Holmes DR Jr. Drug-eluting coronary-artery stents. N Engl J Med 2013;368:254-65.

2 Palmerini T, Biondi-Zoccai G, Della Riva D, Stettler C, Sangiorgi D, D'Ascenzo F, Kimura T, Briguori C, Sabatè M, Kim HS, De Waha A, Kedhi E, Smits PC, Kaiser C, Sardella G, Marullo A, Kirtane AJ, Leon MB, Stone GW. Stent thrombosis with drug-eluting and bare-metal stents: evidence from a comprehensive network metaanalysis. Lancet 2012;379:1393-402.

3 Marroquin OC, Selzer F, Mulukutla SR, Williams DO, Vlachos HA, Wilensky RL, Tanguay JF, Holper EM, Abbott JD, Lee JS, Smith C, Anderson WD, Kelsey SF, Kip KE. A comparison of bare-metal and drug-eluting stents for off -label indications. N Engl J Med 2008; 358: 342-52

4 Windecker S, Kolh P, Alfonso F, Collet JP, Cremer J, Falk V, Filippatos G, Hamm C, Head SJ, Jüni P, Kappetein AP, Kastrati A, Knuuti J, Landmesser U, Laufer G, Neumann FJ, Richter DJ, Schauerte P, Sousa Uva M, Stefanini GG, Taggart DP, Torracca L, Valgimigli M, Wijns W, Witkowski A. 2014 ESC/EACTS Guidelines on myocardial revascularization: The Task Force on Myocardial Revascularization of the European Society of Cardiology (ESC) and the European Association for Cardio-Thoracic Surgery (EACTS)Developed with the special contribution of the European Association of Percutaneous Cardiovascular Interventions (EAPCI). Eur Heart J 2014;35:2541-619.

5 Cassese S, Byrne RA, Tada T, Pinieck S, Joner M, Ibrahim T, King LA, Fusaro M, Laugwitz KL, Kastrati A. Incidence and predictors of restenosis after coronary stenting in 10,004 patients with surveillance angiography. Heart 2014;100:153-9. 
6 Scheller B, Hehrlein C, Bocksch W, Rutsch W, Haghi D, Dietz U, Böhm M, Speck

U. Treatment of coronary in-stent restenosis with a paclitaxel-coated balloon catheter. N Engl J Med 2006; 355:2113-2124.

7 Scheller B, Hehrlein C, Bocksch W, Rutsch W, Haghi D, Dietz U, Böhm M, Speck U. Two year follow-up after treatment of coronary in-stent restenosis with a paclitaxel-coated balloon catheter, Clin Res Cardiol 2008;97:773-781.

8 Scheller B, Clever YP, Kelsch B, et al. Long-term follow-up after treatment of coronary in-stent restenosis with a Paclitaxel-coated balloon catheter. JACC Cardiovasc Interv 2012;5:323-330

9 Habara S, Iwabuchi M, Inoue N, Nakamura S, Asano R, Nanto S, Hayashi Y, Shiode N, Saito S, Ikari Y, Kimura T, Hosokawa J, Nakamura M, Kotani J, Kozuma K, Mitsudo K. A multicenter randomized comparison of paclitaxel-coated balloon catheter with conventional balloon angioplasty in patients with bare-metal stent restenosis and drug-eluting stent restenosis. Am Heart J 2013;166:527-33

10 Unverdorben M, Vallbracht C, Cremers B, Heuer H, Hengstenberg C, Maikowski C, Werner GS, Antoni D, Kleber FX, Bocksch W, Leschke M, Ackermann H, Boxberger M, Speck U, Degenhardt R, Scheller B. Paclitaxel-coated balloon catheter versus paclitaxel-coated stent for the treatment of coronary in-stent restenosis, Circulation 2009;119:2986-2994

11 Habara S, Mitsudo K, Kadota K, Goto T, Fujii S, Yamamoto H, Katoh H, Oka N, Fuku Y, Hosogi S, Hirono A, Maruo T, Tanaka H, Shigemoto Y, Hasegawa D, Tasaka H, Kusunose M, Otsuru S, Okamoto Y, Saito N, Tsujimoto Y, Eguchi H, Miyake K, Yoshino M. Effectiveness of Paclitaxel-eluting balloon catheter in patients with Sirolimus-eluting stent restenosis. JACC Cardiovasc Interv 2011;4:149-154. 
12 Rittger H, Brachmann J, Sinha AM, Waliszewski M, Ohlow M, Brugger A, Thiele H, Birkemeyer R, Kurowski V, Breithardt OA, Schmidt M, Zimmermann S, Lonke S, von Cranach M, Nguyen TV, Daniel WG, Wöhrle J. A Randomized, Multicenter, Single-Blinded Trial Comparing Paclitaxel-Coated Balloon Angioplasty With Plain Balloon Angioplasty in Drug-Eluting Stent Restenosis: The PEPCAD-DES Study. J Am Coll Cardiol 2012;59:1377-1382

13 Xu B, Gao R, Wang J, Yang Y, Chen S, Liu B, Chen F, Li Z, Han Y, Fu G, Zhao Y, Ge J. A prospective, multicenter, randomized trial of paclitaxel-coated balloon versus paclitaxel-eluting stent for the treatment of drug-eluting stent in-stent restenosis: results from the PEPCAD China ISR trial. JACC Cardiovasc Interv 2014;7:204-11.

14 Byrne RA, Neumann FJ, Mehilli J, Pinieck S, Wolff B, Tiroch K, Schulz S, Fusaro M, Ott I, Ibrahim T, Hausleiter J, Valina C, Pache J, Laugwitz KL, Massberg S, Kastrati A. Paclitaxel-eluting balloons, paclitaxel-eluting stents, and balloon angioplasty in patients with restenosis after implantation of a drug-eluting stent (ISAR-DESIRE 3): a randomised, open-label trial. Lancet. 2013;381:461-467.

15 Wöhrle J, Zadura M, Möbius-Winkler S, Leschke M, Opitz C, Ahmed W, Barragan P, Simon JP, Cassel G, Scheller B. SeQuent Please World Wide Registry: Clinical Results of SeQuent Please Paclitaxel-Coated Balloon Angioplasty in a Large-Scale, Prospective Registry Study. J Am Coll Cardiol 2012;60:1733-1738.

16 Zeymer U, Waliszewski M, Spiecker M, Gastmann O, Faurie B, Ferrari M, Alidoosti M, Palmieri C, Heang TN, Ong PJ, Dietz U. Prospective 'real world' registry for the use of the 'PCB only' strategy in small vessel de novo lesions. Heart 2014;100:311-6 
17 Mehran R, Dangas G, Abizaid AS, Mintz GS, Lansky AJ, Satler LF, Pichard AD, Kent KM, Stone GW, Leon MB. Angiographic patterns of in-stent restenosis: classification and implications for long-term outcome. Circulation. 1999;100:1872-8.

18 Cutlip D, Windecker S, Mehran R, , Boam A, Cohen DJ, van Es GA, Steg PG, Morel MA, Mauri L, Vranckx P, McFadden E, Lansky A, Hamon M, Krucoff MW, Serruys PW. Clinical end points in coronary stent trials: a case for standardized definitions. Circulation 2007;115:2344-2351.

19 Kleber FX, Mathey DG, Rittger H, Scheller B. German Drug-eluting Balloon Consensus Group. How to use the drug-eluting balloon: recommendations by the German consensus group. EuroIntervention 2011;7 Suppl K:K125-8.

20 Dangas GD, Claessen BE, Caixeta A, Sanidas EA, Mintz GS, Mehran R. In-stent restenosis in the drug-eluting stent era. J Am Coll Cardiol 2010;56:1897-907.

21 Alfonso F, Byrne RA, Rivero F, Kastrati A. Current treatment of in-stent restenosis. J Am Coll Cardiol 2014;63:2659-73.

22 Latib A, Mussardo M, Ielasi A, Tarsia G, Godino C, Al-Lamee R, Chieffo A, Airoldi F, Carlino M, Montorfano M, Colombo A. Long-term outcomes after the percutaneous treatment of drug-eluting stent restenosis. JACC Cardiovasc Interv 2011;4:155-64.

23 Alfonso F, Pérez-Vizcayno MJ, Cárdenas A, García Del Blanco B, Seidelberger B, Iñiguez A, Gómez-Recio M, Masotti M, Velázquez MT, Sanchís J, GarcíaTouchard A, Zueco J, Bethencourt A, Melgares R, Cequier A, Dominguez A, Mainar V, López-Mínguez JR, Moreu J, Martí V, Moreno R, Jiménez-Quevedo P, Gonzalo N, Fernández C, Macaya C. A randomized comparison of drug-eluting balloon versus everolimus-eluting stent in patients with bare-metal stent-in-stent 
restenosis: the RIBS V Clinical Trial (Restenosis Intra-stent of Bare Metal Stents: paclitaxel-eluting balloon vs. everolimus-eluting stent). J Am Coll Cardiol 2014;63:1378-86.

24 Mehilli J, Byrne RA, Tiroch K, Pinieck S, Schulz S, Kufner S, Massberg S, Laugwitz KL, Schömig A, Kastrati A. Randomized Trial of Paclitaxel- Versus Sirolimus-Eluting Stents for Treatment of Coronary Restenosis in SirolimusEluting Stents The ISAR-DESIRE 2 (Intracoronary Stenting and Angiographic Results: Drug Eluting Stents for In-Stent Restenosis 2) Study. J Am Coll Cardiol $2010 ; 55: 2710-6$.

25 Alfonso F, Pérez-Vizcayno MJ, Dutary J, Zueco J, Cequier A, García-Touchard A, Martí V, Lozano I, Angel J, Hernández JM, López-Mínguez JR, Melgares R, Moreno R, Seidelberger B, Fernández C, Hernandez R. Implantation of a drugeluting stent with a different drug (switch strategy) in patients with drug-eluting stent restenosis. Results from a prospective multicenter study (RIBS III [Restenosis Intra-Stent: Balloon Angioplasty Versus Drug-Eluting Stent]). J Am Coll Cardiol Intv 2012;5:728 -37.

26 Indermuehle A, Bahl R, Lansky AJ, Froehlich GM, Knapp G, Timmis A, Meier P. Drug-eluting balloon angioplasty for in-stent restenosis: a systematic review and meta-analysis of randomised controlled trials. Heart 2013;99:327-33.

27 Piccolo R, Galasso G, Piscione F, Esposito G, Trimarco B, Dangas GD, Mehran R. Meta-analysis of randomized trials comparing the effectiveness of different strategies for the treatment of drug-eluting stent restenosis. Am J Cardiol 2014;114:1339-46. 
28 Almalla M, Schröder J, Pross V, Marx N, Hoffmann R. Paclitaxel-eluting balloon versus everolimus-eluting stent for treatment of drug-eluting stent restenosis. Catheter Cardiovasc Interv 2014;83:881-7.

29 Castagna MT, Mintz GS, Leiboff BO, Ahmed JM, Mehran R, Satler LF, Kent KM, Pichard AD, Weissman NJ. The contribution of "mechanical" problems to in-stent restenosis: An intravascular ultrasonographic analysis of 1090 consecutive in-stent restenosis lesions. Am Heart J 2001;142:970-4.

30 Kang SJ, Mintz GS, Park DW, Lee SW, Kim YH, Whan Lee C, Han KH, Kim JJ, Park SW, Park SJ. Mechanisms of in-stent restenosis after drug-eluting stent implantation: intravascular ultrasound analysis. Circ Cardiovasc Interv 2011;4:914. 


\section{Figure legends}

Figure 1-Rates of major adverse cardiac events, target lesion revascularization, myocardial infarction and cardiac death according to the type of drug-eluting stent in-stent restenosis.

$\mathrm{ISR}=$ in-stent restenosis; $\mathrm{MACE}=$ major adverse cardiac events; $\mathrm{MI}=$ myocardial infarction; $\mathrm{PES}=$ paclitaxel-eluting stent; TLR= target lesion revascularization.

Figure 2-Kaplan Meier time-to-event curves showing cumulative rates of major adverse cardiac events, target lesion revascularization, myocardial infarction and cardiac death with comparison of cumulative rates according to the type of drug-eluting stent in-stent restenosis.

$\mathrm{ISR}=$ in-stent restenosis; $\mathrm{MACE}=$ major adverse cardiac events; $\mathrm{MI}=$ myocardial infarction; $\mathrm{PES}=$ paclitaxel-eluting stent; $\mathrm{TLR}=$ target lesion revascularization.

Figure 3- Adjusted odds-ratio and corresponding 95\% confidence intervals for major adverse cardiac events.

$\mathrm{CI}=$ confidence interval; $\mathrm{DES}=$ drug-eluting stents; $\mathrm{ISR}=$ in-stent restenosis; $\mathrm{MACE}=$ major adverse cardiac events; $\mathrm{OR}=$ odds-ratio $\mathrm{PES}=$ paclitaxel-eluting stent.

Reference categories are: non PES-ISR; DES-ISR delay $<1$ year; focal ISR, no diabetes mellitus, no hypertension, no hyperlipidemia. 


\section{Appendix}

List of participating centers: Centre Hospitalier Universitaire d'Angers; Centre Hospitalier d'Avignon; Centre Hospitalier de Bourges; Centre Hospitalier de Chartres; Centre Hospitalier de Colmar; Centre Hospitalier Universitaire Nord de Marseille; Centre Hospitalier Universitaire de Montpellier; Polyclinique les Fleurs Ollioules; Centre Hospitalier de Pau; Centre Hospitalier Universitaire de Rennes; Centre Hospitalier Universitaire de Rouen; Clinique Saint-Hilaire Rouen; Centre Hospitalier Universitaire de Toulouse. 


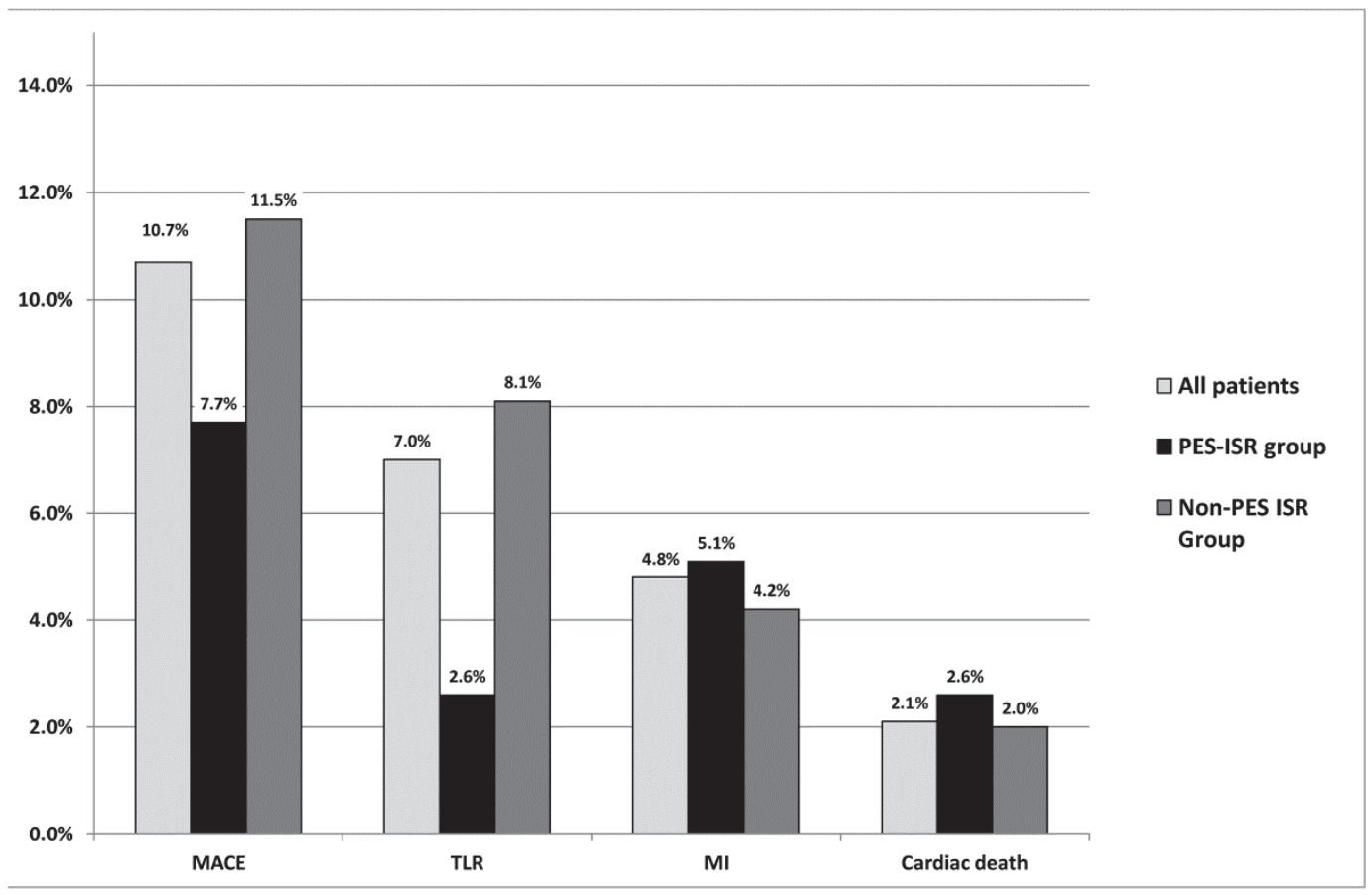

Fig. 1 


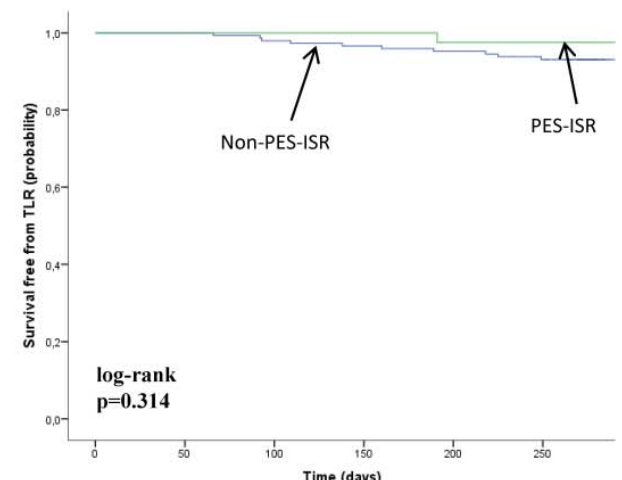

No at risk:

Non PES-ISR 164

PES-ISR

164
42

159

154

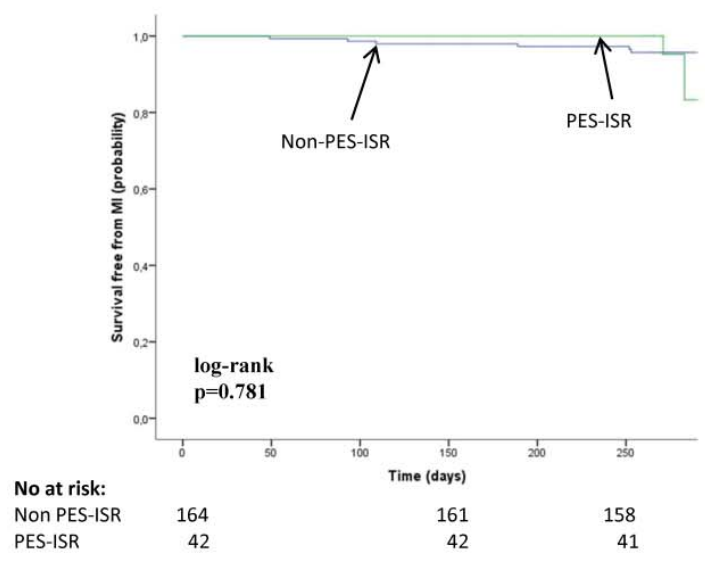

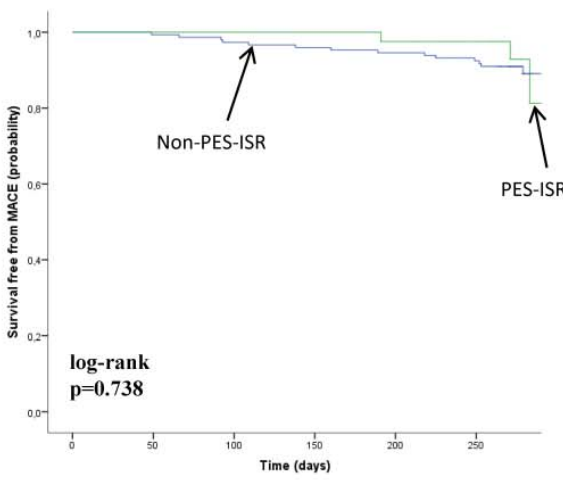

No at risk:

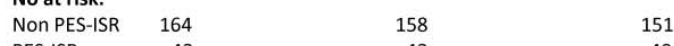

PES-ISR 42

42

151
40

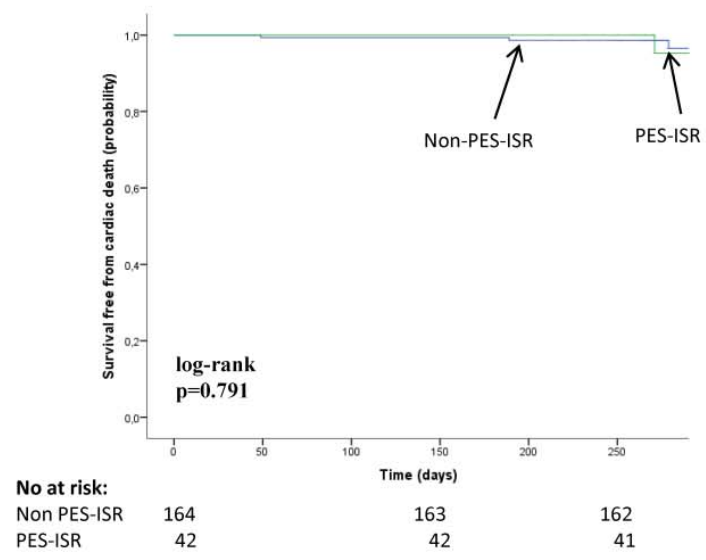

Fig. 2 


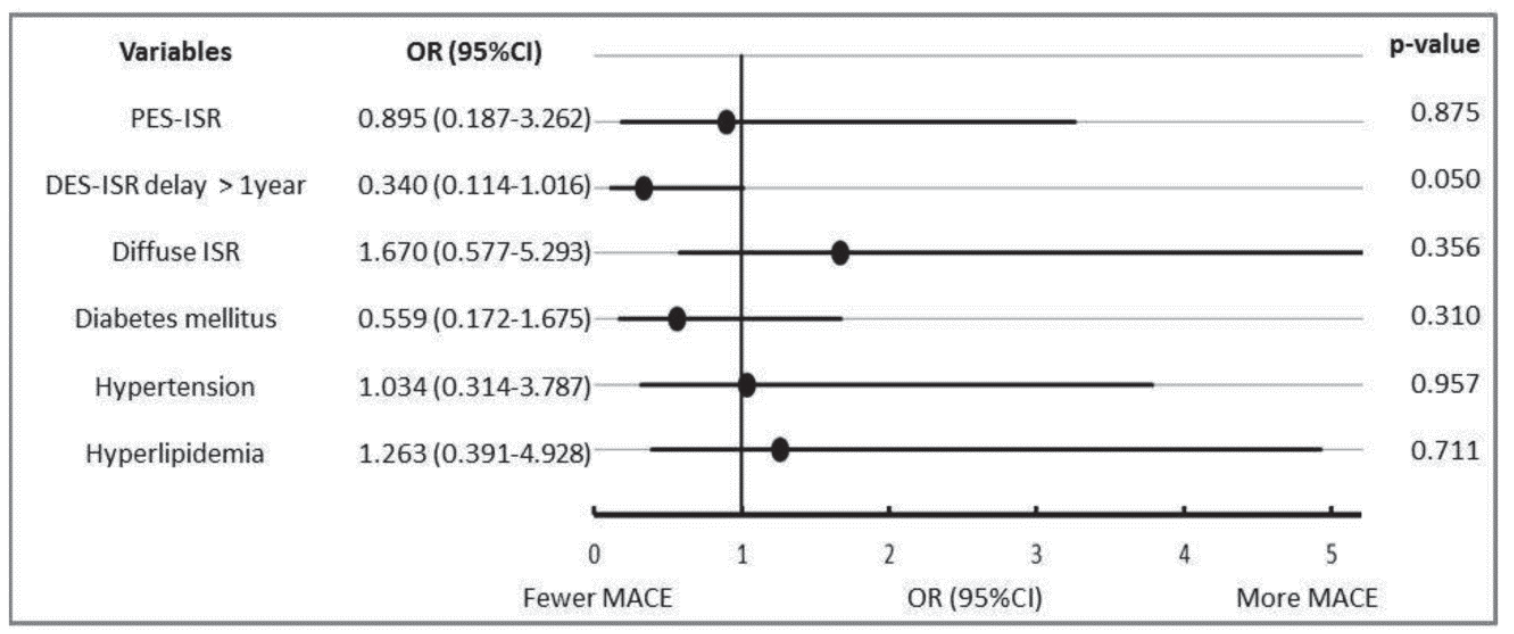

Fig. 3 
Table 1 Baseline demographic characteristics.

\begin{tabular}{lcccc}
\hline & $\begin{array}{c}\text { All patients } \\
(\mathrm{n}=206)\end{array}$ & $\begin{array}{c}\text { PES-ISR group } \\
(\mathrm{n}=42)\end{array}$ & $\begin{array}{c}\text { Non PES-ISR } \\
\text { group }(\mathrm{n}=164)\end{array}$ & p-value \\
\hline Age, yrs & $67.7 \pm 10.2$ & $66.9 \pm 11.4$ & $67.9 \pm 9.9$ & 0.586 \\
Male & $166(80.6)$ & $36(85.7)$ & $130(79.3)$ & 0.341 \\
Diabete mellitus & $85(41.3)$ & $14(33.3)$ & $71(43.3)$ & 0.242 \\
Hypertension & $143(69.4)$ & $27(64.3)$ & $116(70.7)$ & 0.419 \\
Hyperlipidemia & $156(75.7)$ & $35(83.3)$ & $121(73.8)$ & 0.198 \\
Current smoker & $97(47.1)$ & $22(52.4)$ & $75(45.7)$ & 0.441 \\
End stage renal disease & $11(5.3)$ & $1(2.4)$ & $10(6.1)$ & 0.339 \\
Stress test available & $65(31.6)$ & $11(26.2)$ & $54(32.9)$ & 0.402 \\
Positive stress test & $63(96.9)$ & $11(100)$ & $52(96.3)$ & 0.517 \\
Unstable angina & $80(38.8)$ & $71(43.3)$ & $9(21.4)$ & 0.009 \\
Non-STEMI & $26(12.6)$ & $7(16.7)$ & $19(11.6)$ & 0.376 \\
STEMI & $8(3.9)$ & $0(0.0)$ & $8(4.9)$ & 0.144 \\
ISR delay, yrs & $3.0 \pm 2.4$ & $3.2 \pm 2.2$ & $3.0 \pm 2.4$ & 0.558 \\
\hline
\end{tabular}

Values are mean \pm SD or $\mathrm{n}(\%)$.

$\mathrm{ISR}=$ in-stent restenosis; $\mathrm{PES}=$ paclitaxel-eluting stent; STEMI= ST-elevation myocardial infarction. 
Table 2 Baseline angiographic characteristics.

\begin{tabular}{|c|c|c|c|c|}
\hline & $\begin{array}{c}\text { All } \\
\text { patients/lesions } \\
(\mathrm{n}=206 / 210)\end{array}$ & $\begin{array}{c}\text { PES-ISR } \\
\text { group } \\
(n=42 / 43)\end{array}$ & $\begin{array}{c}\text { Non PES-ISR } \\
\text { group }(\mathrm{n}=164 / 167)\end{array}$ & p-value \\
\hline Diagnostic coronary findings & & & & 0.524 \\
\hline Single-vessel disease & $117(56.8)$ & $27(64.3)$ & $90(54.9)$ & \\
\hline Two-vessel disease & $53(25.7)$ & $8(19.0)$ & $45(27.4)$ & \\
\hline Three-vessel disease & $36(17.5)$ & $7(16.7)$ & $29(17.7)$ & \\
\hline Target vessel & & & & 0.318 \\
\hline LAD & $79(37.6)$ & $18(41.9)$ & $61(36.5)$ & \\
\hline LCX & $58(27.6)$ & $13(30.9)$ & $45(26.9)$ & \\
\hline RCA & $61(29.0)$ & $12(27.2)$ & $49(29.3)$ & \\
\hline Other & $12(5.7)$ & $0(0)$ & $12(7.2)$ & \\
\hline Target stent ${ }^{\mathrm{i}}$ & & & & $<0.001$ \\
\hline PES & $43(21.2)$ & $43(100)$ & 0 & \\
\hline SES & $78(38.4)$ & $0(0)$ & $78(48.8)$ & \\
\hline ZES & $12(5.9)$ & $0(0)$ & $12(7.5)$ & \\
\hline EES & $59(29.1)$ & $0(0)$ & $59(36.9)$ & \\
\hline BES & $6(3.0)$ & $0(0)$ & $6(3.7)$ & \\
\hline Other & $5(2.5)$ & $0(0)$ & $5(3.1)$ & \\
\hline ISR classification $^{\mathrm{ii}}$ & & & & 0.706 \\
\hline Articulation/Gap & $2(1.0)$ & $1(2.4)$ & $1(0.6)$ & \\
\hline Focal margin & $21(10.2)$ & $4(9.8)$ & $17(10.4)$ & \\
\hline Focal body & $79(38.5)$ & $14(34.1)$ & $65(39.6)$ & \\
\hline Multifocal & $10(4.9)$ & $1(2.4)$ & $9(5.5)$ & \\
\hline Diffuse & $71(34.6)$ & $18(43.9)$ & $53(32.3)$ & \\
\hline Proliferative & $15(7.3)$ & $2(4.9)$ & $13(7.9)$ & \\
\hline Occlusive & $7(3.4)$ & $1(2.4)$ & $6(3.7)$ & \\
\hline Diffuse ISR pattern & $93(44.3)$ & $21(48.8)$ & $72(43.1)$ & 0.606 \\
\hline \multicolumn{5}{|l|}{ Target lesion characteristics } \\
\hline TIMI flow 0 or 1 & $16(7.6)$ & $3(7.0)$ & $13(7.8)$ & 1.000 \\
\hline B2-C lesion & $72(34.3)$ & $18(41.9)$ & $54(32.3)$ & 0.281 \\
\hline
\end{tabular}

Values are mean \pm SD or $\mathrm{n}(\%)$

$\mathrm{BES}=$ biolimus-eluting stent; $\mathrm{EES}=$ everolimus-eluting stent; $\mathrm{LAD}=$ left anterior descending artery; $\mathrm{LCX}=$ left circumflex; $\mathrm{RCA}=$ right coronary artery; $\mathrm{SES}=$ sirolimus-eluting stent; $\mathrm{TIMI}=$ thrombolysis in myocardial infarction; $\mathrm{ZES}=$ zotarolimus-eluting stent. Other abbreviations as in table 1.

${ }^{\mathrm{i}}$ Percentage of lesions with data available about target stent type $(\mathrm{n}=203)$.

${ }^{i i}$ Percentage of lesions with data available about ISR classification $(n=205)$. 
Table 3 Quantitative coronary analysis* .

$\begin{array}{cccc}\text { All lesions } & \text { PES-ISR group } & \text { Non PES-ISR } & \text { p-value } \\ (\mathrm{n}=163 / 210) & (\mathrm{n}=36 / 43) & \text { group } & \end{array}$

$(\mathrm{n}=127 / 167)$

Before index procedure

\begin{tabular}{lcccc}
\hline Lesion length, $\mathrm{mm}$ & $12.59 \pm 8.87$ & $15.02 \pm 12.61$ & $11.99 \pm 7.4$ & 0.07 \\
& & & $2.78 \pm 0.84$ & 0.033 \\
\hline Reference vessel diameter, $\mathrm{mm}$ & $2.77 \pm 0.78$ & $2.74 \pm 0.55$ & & 0.021 \\
\hline Minimal lumen diameter, $\mathrm{mm}$ & $0.98 \pm 0.47$ & $1.13 \pm 0.40$ & $0.92 \pm 0.48$ & \\
\hline Diameter stenosis, \% & $65.1 \pm 17.0$ & $57.5 \pm 17.2$ & $67.2 \pm 16.4$ & 0.002
\end{tabular}

\begin{tabular}{lcccc}
\hline Post-index procedure & & & \\
\hline \multicolumn{2}{l}{} & & & \\
\hline Reference vessel diameter, $\mathrm{mm}$ & $2.78 \pm 0.52$ & $2.72 \pm 0.45$ & $2.80 \pm 0.54$ & 0.446 \\
\hline Minimal lumen diameter, $\mathrm{mm}$ & $2.37 \pm 0.55$ & $2.22 \pm 0.57$ & $2.39 \pm 0.54$ & 0.262 \\
\hline Diameter stenosis, \% & $15.6 \pm 12.5$ & $14.6 \pm 11.1$ & $15.9 \pm 12.8$ & 0.575 \\
& & & & \\
\hline
\end{tabular}

*Based on angiographic data from patients with sufficient quality for analysis. 
Table 4 Procedural and device characteristics.

\begin{tabular}{lcccc}
\hline & $\begin{array}{c}\text { All lesions } \\
(\mathrm{n}=210)\end{array}$ & $\begin{array}{c}\text { PES-ISR } \\
\text { group }(\mathrm{n}=43)\end{array}$ & $\begin{array}{c}\text { Non PES-ISR } \\
\text { group }(\mathrm{n}=167)\end{array}$ & p-value \\
\hline Balloon pre-dilation & $195(92.9)$ & $41(95.3)$ & $154(92.2)$ & 0.477 \\
Number of PCB used & 227 & 45 & 182 & - \\
Paclitaxel-coated balloon & & & & \\
\hline \multicolumn{1}{c}{ Diameter, mm } & $3.0 \pm 0.36$ & $2.97 \pm 0.42$ & $3.0 \pm 0.34$ & 0.305 \\
\hline \multicolumn{1}{c}{ Length, mm } & $19.5 \pm 4.9$ & $20.3 \pm 5.8$ & $19.3 \pm 4.6$ & 0.816 \\
\hline \multicolumn{1}{c}{ Inflation pressure, bar } & $12.6 \pm 3.7$ & $13.4 \pm 4.8$ & $12.4 \pm 3.4$ & 0.075 \\
Post-PCB dissection & $3(1.4)$ & $2(4.7)$ & $1(0.6)$ & 0.046 \\
Procedural success & $207(98.6)$ & $2(4.7)$ & $1(0.6)$ & 0.046 \\
Additional stenting & $6(2.9)$ & $2(4.7)$ & $4(2.4)$ & 0.428 \\
Multivessel PCI & $28(13.3)$ & $5(11.6)$ & $23(13.8)$ & 0.712 \\
\hline
\end{tabular}

Values are mean $\pm \mathrm{SD}$ or $\mathrm{n}(\%)$.

$\mathrm{PCI}=$ percutaneous coronary intervention; $\mathrm{PCB}=$ paclitaxel-coated balloon. Other abbreviations as in table 1 and 2. 
Table 5 Clinical outcomes.

\begin{tabular}{lcccc}
\hline & $\begin{array}{c}\text { All patients } \\
(\mathrm{n}=206)\end{array}$ & $\begin{array}{c}\text { PES-ISR group } \\
(\mathrm{n}=42)\end{array}$ & $\begin{array}{c}\text { Non PES-ISR } \\
\text { group (n=164) }\end{array}$ & p-value \\
\hline In-hospital events & $1(0.5)$ & $0(0.0)$ & $1(0.6)$ & 0.612 \\
\hline Death & $0(0.0)$ & $0(0.0)$ & $0(0.0)$ & - \\
\hline Cardiac death & $1(0.5)$ & $0(0.0)$ & $1(0.6)$ & 0.612 \\
\hline Myocardial infarction & $2(1.0)$ & $0(0.0)$ & $0(0.0)$ & 0.472 \\
\hline Target lesion revascularization & $2(1.0)$ & $0(0.0)$ & $2(1.2)$ & 0.472 \\
\hline PCI & $0(0.0)$ & $0(0.0)$ & $0(0.0)$ & - \\
\hline CABG & $9(4.4)$ & $2(4.8)$ & $7(4.3)$ & 0.889 \\
\hline Target vessel revascularization & $3(1.5)$ & $0(0.0)$ & $3(1.8)$ & 0.377 \\
\hline Composite MACE & $(\mathrm{n}=187)$ & $36(92.3)$ & $131(88.5)$ & - \\
\hline Events at 9 months & $5(2.7)$ & $2(5.1)$ & $3(2.0)$ & 0.279 \\
\hline Death & $4(2.1)$ & $1(2.6)$ & $3(2.0)$ & 0.837 \\
\hline Cardiac death & $9(4.8)$ & $2(5.1)$ & $7(4.2)$ & 0.918 \\
\hline Myocardial infarction & $13(7.0)$ & $1(2.6)$ & $12(8.1)$ & 0.226 \\
\hline Target lesion revascularization & $11(5.9)$ & $1(2.6)$ & $10(6.8)$ & 0.322 \\
\hline PCI & $3(1.6)$ & $0(0.0)$ & $3(2.0)$ & 0.370 \\
\hline CABG & $19(10.2)$ & $3(7.7)$ & $16(10.8)$ & 0.566 \\
\hline Composite MACE & $20(10.7)$ & $3(7.7)$ & $17(11.5)$ & 0.495 \\
\hline Valget vessel revascularization & & & & \\
\hline Com & & & & \\
\hline
\end{tabular}

Values are $\mathrm{n}(\%)$.

$\mathrm{CABG}=$ coronary artery bypass graft $\mathrm{MACE}=$ major adverse cardiac events. Other abbreviations as in table 1 and 3. 
Table 6 Comparison of pre- and post-procedural MLD, reference vessel diameters, diameter stenosis, TLR and MACE rates in PCB groups across studies investigating treatment of DESISR.

$\begin{array}{cccccc}\text { GARO } & \text { Habara et } & \text { PEPCAD } & \text { ISAR } & \text { Habara et } & \text { PEPCAD China } \\ \text { Registry } & \text { al. }^{11} & \text { DES }^{12} & \text { DESIRE 3 } & \text { al }^{14} & \text { ISR }^{13}\end{array}$

Pre-procedural

MLD, mm

$0.98 \pm 0.47 \quad 0.99 \pm 0.32 \quad 0.66 \pm 0.40$

$0.97 \pm 0.50$

$0.87 \pm 0.40$

$0.85 \pm 0.38$

Post-procedural

MLD, mm

$2.37 \pm 0.55 \quad 1.99 \pm 0.32 \quad 2.15 \pm 0.42$

$2.29 \pm 0.44$

$1.87 \pm 0.37$

$2.39 \pm 0.37$

Reference vessel

diameter, $\mathrm{mm}$

$2.78 \pm 0.52$

$2.74 \pm 0.34$

$2.92 \pm 2.47$

$2.75 \pm 0.5$

$2.49 \pm 0.50$

$2.59 \pm 0.40$

Post-procedural diameter stenosis, $\%$

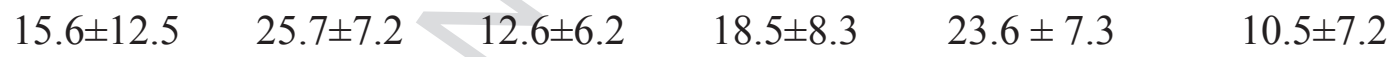

TLR, $\%{ }^{*}$ 7.0

15.3

22.1

2.9

MACE, $\%{ }^{*}$

10.7

4.3

16.7

23.5

6.6

16.5

\section{$\mathrm{DES}=$ Drug-eluting stent; ISAR-DESIRE $3=$ Intracoronary Stenting and Angiographic}

Results: Drug Eluting Stents for In-Stent Restenosis 3; MLD=Minimal lumen diameter; PEPCADChina ISR $=$ A Prospective, Multicenter, Randomized Trial of Paclitaxel-Coated Balloon versus Paclitaxel-Eluting Stent for the Treatment of Drug-eluting Stent In-Stent Restenosis; PEPCAD DES=Treatment of DES-In-Stent Restenosis With SeQuent ${ }^{\circledR}$ Please Paclitaxel Eluting PTCA Catheter; TLR=Target lesion revascularization. Other abbreviations as in tables 1, 2, 4 and 5.

*Time of follow-up was 6 months for Habara et al ${ }^{9,11}$ and PEPCAD DES ${ }^{12} ; 9$ months for PEPCAD China ISR ${ }^{13}$ and the GARO registry and 12 months for ISAR-DESIRE $3^{14}$. 